\title{
Motion Analysis of Pitching Machine for Basketball of MATLAB
}

\author{
Yang Wen-Xian ${ }^{*}$ \\ College of Physical Education of Henan Normal University, Xinxiang 453007, China
}

\begin{abstract}
Basketball is one of the influential sports, and a competitive sport to score and prevent the opponent from scoring. Shooting is the most common and simplest means to score, but there is strict requirement of shooting accuracy for basketball player. The paper presents a type of pitching mechanism for basketball designed according to technical principle for passing and catching in basketball as well as stresses state analysis of motion process of basketball shooting in detail, and builds a mathematical model for motion process to carry out special analysis and summary based on MATLAB simulation principle, so as to determine the key parameters such as catching point and position of basketball player in shooting training, achieving the best passing effect and providing practical convenience for basketball player in training.
\end{abstract}

Keywords: MATLAB, motion analysis, pitching machine for basketball.

\section{INTRODUCTION}

Shooting is a basic skill for every basketball player which has no strict requirement factors such as physical quality and talent on basketball player, the only way to standardize act of shooting and improve hit rate is the systemic practice.

A professional basketball player shall carry out shooting training almost every day for $500-800$ times. Some players may carry out additional training, with shooting for more than 1000 times.

At present, ladder players are needed to pick up and pass the balls in shooting training, given that training for many times, the workload for ladder players is huge. If there is significant decline in physical strength, passing shall be influenced, and shooting tempo is more likely to be interrupted, thus influencing the training effect [1]. Therefore, it is necessary to develop a new type of pitching machine for basketball to ensure high quality passing in succession based on sufficient understanding of shooting and passing and basketball motion process, so as not only to alleviate pressure on ladder players, but also to improve shooting quality and efficiency.

\section{PITCHING MECHANISM}

For basketball, chest passing with two hands is in common use in practice, which can enhance passing velocity and strength to a great extent and be completed at any angle and range, becoming the main connection mode in tactics. A basketball player shall complete many times of chest passing in a basketball game. First, basketball player shall place the basketball front chest and stretch outward elbows, then straighten forearms to pass the basketball, at this point, the player shall stride forward a half step [2]. Fingers should toward the upper front when the ball is off hands. The passing velocity is dependent on strength of arms, the passing direction is dependent on direction of both hands, the chest passing is as shown in Fig. (1).

According to the technical movement of chest passing with both hands, the passing process may be simplified that the basketball generates an initial velocity as a result of friction in both hands, and the initial velocity and fingers direction are in a straight line, based on which, a dual wheel type pitching mechanism is built with basic principle of counterrotating dual wheel, its structure is as shown in Fig. (2).

The two friction wheels are in operation driven by motor, when basketball enters the track, it shall move toward the mid position of friction wheels along with the track, at this point, the basketball shall keep moving forward under the continuous friction force of friction wheels. The basketball shall have an initial velocity after thoroughly departing from the friction wheels, which is indicated by $\mathrm{v}_{0}$;

There is an angle between middle axis of friction wheels and the ground; accordingly, after shooting of basketball, there is a horizontal included angle, which is indicated by $\theta$.

According to the basic principle shown in Fig. (2), when the motorstarts to rotate, the friction wheels shall be in operation accordingly, and the basketball shall obtain kineticenergy to shoot out [3].

The shooting principle is completely simple and practical to ensure stability and accurate control of shooting velocity and angle, making players catch the ball in a comfortable way and improving training quality.

Suppose the real time velocity of wheels are $\omega 1$ and $\omega 2$, the radius of wheel is $R$, based on which the linear velocity of wheel in normal motion condition is calculated by $\mathrm{v} 1=\omega 1 \mathrm{R} ; \mathrm{v} 2=\omega 2 \mathrm{R}$, then the initial velocity $\mathrm{v} 0$ of basketball at shooting is calculated by $v 0=1 / 2(v 1+v 2)$. Suppose that the actual velocity of two friction wheels is identical, namely, $\mathrm{v} 0=\mathrm{v} 1=\mathrm{v} 2$. Thus, according to calculation of the corresponding angular speed, the initial velocity of basket- 


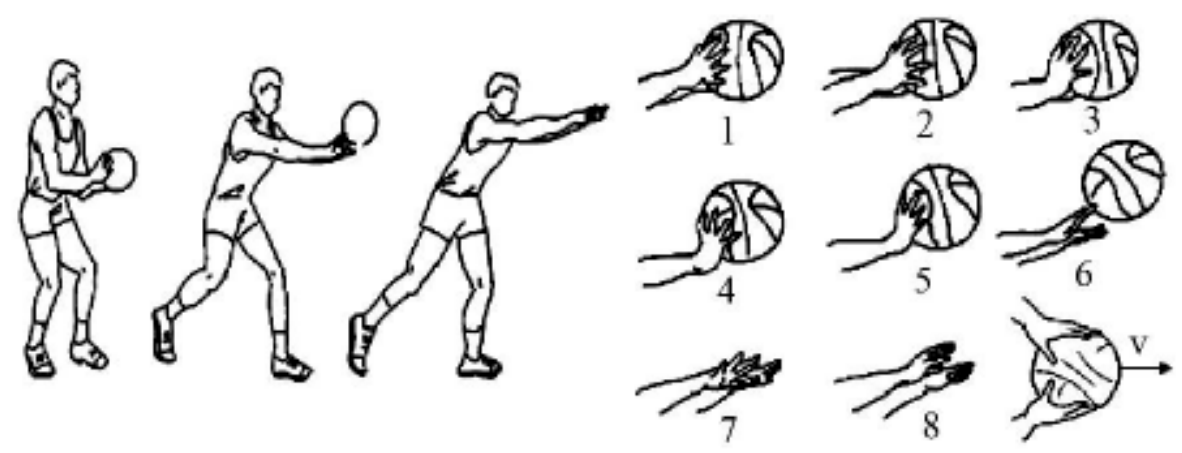

Fig. (1). Schematic diagram for chest passing with both hands.
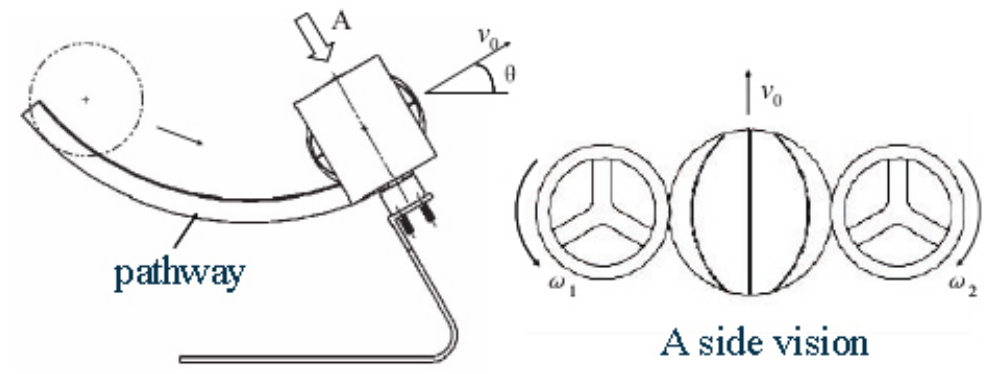

Fig. (2). Schematic diagram for dual wheel type friction pitching mechanism.

ball at shooting shall be calculated, or the actual angular velocity of the friction wheels required is obtained so as to determine the optimal value of motor velocity in the end [4].

\section{MOTION ANALYSIS OF BASKETBALL IN FLY- ING PROCESS}

Basketball is off the player as a result of acting force of both hands during passing and flies out along the direction of fingers of both hands, there is close connection between passing track and the accuracy. The basketball from the above-mentioned pitching mechanism has a certain horizontal included angle and initial speed, and the motion locus of the basketball shall be obtained by building motion model of flying basketball so as to determine whether the basketball is able to reach the hands of player accurately and carry out detailed optimization and rectification for the initial velocity and horizontal angle of basketball shooting.

\subsection{Motion Model of Flying Basketball}

Basketball is shot out due to its kinetic energy obtained from friction force of pitching mechanism, it shall keep flying in air till reaching to the player's hands. During flying process, the basketball shall be influenced by factors such as gravity and resistance. Professional shooting training is carried out in indoor stadium, therefore, the external factors such as wind, rain and snow may not be taken into consideration.

In addition, since passing velocity is not in the influence range of air resistance, accordingly, air resistance can be ignored, so, the basketball, after shooting, shall only be subject to the influence of self gravity [5].

Suppose the basketball is a hollow ball with uniform texture, then the flying locus of the basketball can considered as the motion locus of center of ball. Since the gravity is the only influencing factor, which approximates to perfect state, consequently, the flying motion of basketball is similar to oblique projectile motion, the plan schematic diagram oblique projectile motion is as shown in Fig. (3), and the basketball shooting and motion model are as shown in Fig. (4).

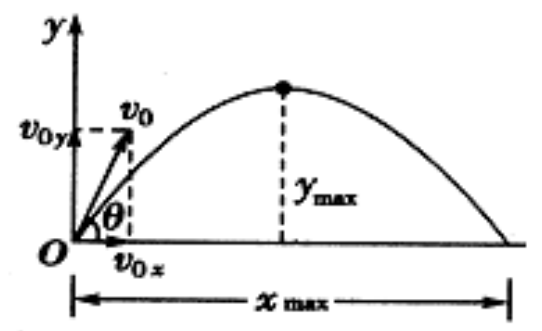

Fig. (3). Plan schematic diagram for oblique projectile motion.

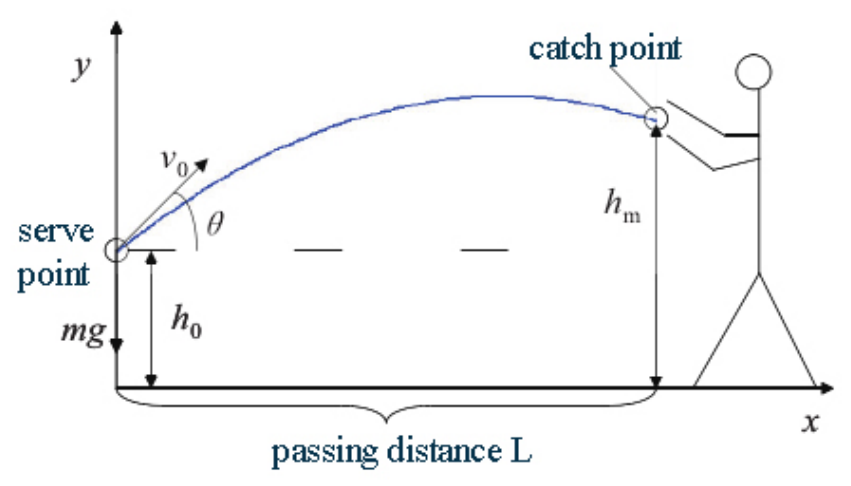

Fig. (4). Schematic diagram for basketball shooting and motion model.

According to the above-mentioned diagram, xoy plane is taken as motion model of the flying basketball, $\mathrm{x}$ is horizon- 
tal axis direction of basketball in flying motion, $\mathrm{y}$ is vertical axis direction of basketball in flying motion, v0 is initial velocity of basketball at shooting, $\theta$ is horizontal angle, $g$ is gravitational acceleration. In the paper, $g$ is $9.8 \mathrm{~m} / \mathrm{s} 2, \mathrm{~m}$ is mass of basketball, h0 is shooting height of basketball, hm is catching height, $\mathrm{L}$ is flying range of basketball after shooting, at the time $t$ of basketball after shooting, the basketball motion is subject to orthogonal decomposition:

Velocity component along horizontal direction: $\mathrm{v}_{\mathrm{x}}=\mathrm{v}_{0} \cos \theta$

Velocity component along vertical direction: $\mathrm{v}_{\mathrm{y}}=\mathrm{v}_{0} \sin \theta-\mathrm{gt}$

Coordinate of basketball (mass point): $\mathrm{x}(\mathrm{t})=\mathrm{v}_{0} \cos (\theta) \mathrm{t}$

$\mathrm{y}(\mathrm{t})=\mathrm{h}_{0}+\mathrm{v}_{0} \sin (\theta) \mathrm{t}-\frac{1}{2} \mathrm{gt}^{2}$

Eliminate $t$ from formula (3) and (4) to obtain the locus formula of basketball:

$\mathrm{y}=\mathrm{x} \tan \theta-\frac{\mathrm{gx}^{2}}{2 \mathrm{v}_{0}^{2} \cos ^{2} \theta}$;

In order to make player catch the ball in specified position $\left(\mathrm{L}, \mathrm{h}_{\mathrm{m}}\right.$ ), namely $\mathrm{x}=\mathrm{L}$ and $\mathrm{y}=\mathrm{h}_{\mathrm{m}}$, at this point, the initial velocity and horizontal included angle of basketball shall satisfy the following relation:

$\mathrm{V}_{0}=\frac{\mathrm{L}}{\cos \theta} \sqrt{\frac{\mathrm{g}}{2\left[\mathrm{~L} \tan \theta-\left(\mathrm{h}_{\mathrm{m}}-\mathrm{h}_{0}\right)\right]}} ;$

\subsection{Model Analysis}

According to the motion model generated in the abovementioned process, in order to catch the basketball from pitching machine, the variables v0 and $\theta$ shall satisfy the relation given in the above-mentioned formula. Player in training needs to change shooting position from time to time instead of training in fixed shooting position, which brings additional requirement to pitching machine; whether v0 has an extreme value or not shall gradually become study focus in the next step [6].

The paper adopts MATLAB simulation technique to carry out specific analysis on the topic and the passing range (L) given in the paper is based on the size of basketball court defined by FIBA, as shown in Fig. (5). The pitching point and center of basket shall be along the same direction, their projection points shall coincide.

The shooting position for player in training shall be selected according to three point line in basketball court, including three-point range and two-point range.

The paper takes the most common positions in shooting training as research objects for analysis, with four positions selected, including penalty line (indicated by L1 and the length is $4.225 \mathrm{~m}$ ), three-point line (indicated by L2 and the length is $6.75 \mathrm{~m}$ ), mid-court line (indicated by L3 and the length is $12.425 \mathrm{~m}$ ) and front court three-point line (indicated by $\mathrm{L}$, the length is $18.1 \mathrm{~m}$ ).

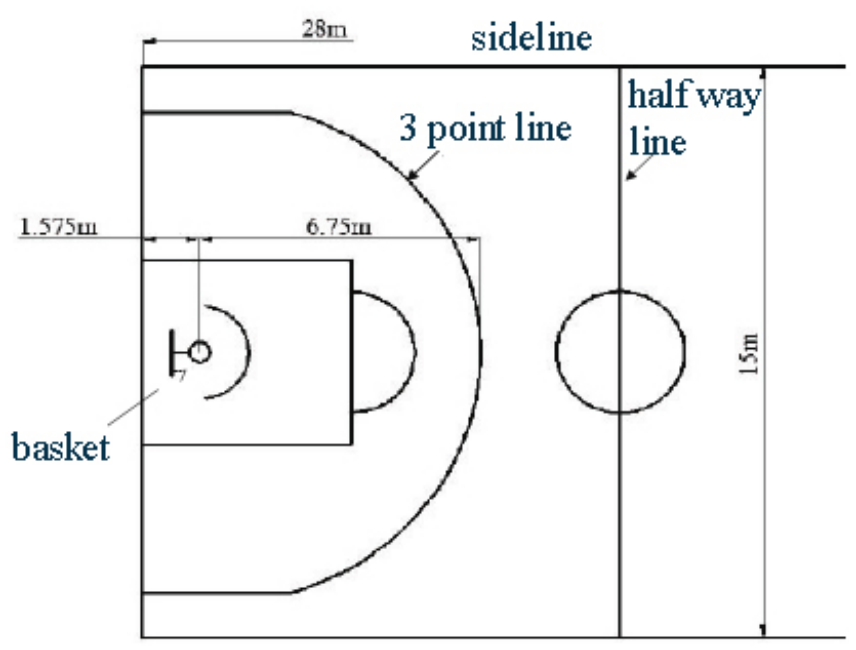

Fig. (5). Schematic diagram for basketball court size defined by FIBA.

The actual pitching height by pitching machine is $1 \mathrm{~m}$, and the catching height is dependent on the actual height from the player's chest to ground, the chest height is usually $85 \%$ of total body height, if the player is $2 \mathrm{~m}$ in body height, then the catching height shall be $1.7 \mathrm{~m}$ [7].

According to the above-mentioned initial conditions, the research on relation of variables based on MATLAB simulation technique is as follows:

$$
\mathrm{L}=6.75 ; \mathrm{g}=9.8 ; \mathrm{h}_{\mathrm{m}}=1.7 ; \mathrm{h} 0=1 \text {; }
$$

$\% \mathrm{~L}$ is distance between shooting point and catching position; $\mathrm{g}$ is gravitational acceleration; $\mathrm{h}_{\mathrm{m}}$ is catching position; $\mathrm{h} 0$ is shooting height of basketball

$$
\begin{aligned}
& \mathrm{h}=\mathrm{h}_{\mathrm{m}}-\mathrm{h}_{0} \text {; } \\
& \text { beta }=\operatorname{atan}(\mathrm{h} / \mathrm{L}) \text {; } \\
& \text { alfa }=[30: 0.01: 70] \text {; } \\
& \text { sita }=\text { pi.*alfa/180; } \\
& \mathrm{a}=\mathrm{L} .{ }^{*} \operatorname{sqrt}(\mathrm{g} / 2) \text {; } \\
& \mathrm{v}_{0}=\mathrm{a} . /((\cos (\text { sita })) . * \operatorname{sqrt}(\mathrm{L} . * \tan (\text { sita })-\mathrm{h})) \text {; } \\
& \text { subplot(2,2,1); }
\end{aligned}
$$

plot $\left(\mathrm{alfa}, \mathrm{v}_{0}\right) ; \%$ Relation curve between shooting angle and velocity;

$$
\begin{aligned}
& \text { xlabel(serve angle } \left.\theta /\left({ }^{\circ}\right) '\right) \\
& \text { ylabel('pitching velocity v0/(m/s)'); }
\end{aligned}
$$

\section{EXPERIMENTAL RESULT}

In order to verify whether there is an extreme value between relation of initial velocity and horizontal included angle and initial velocity in practical shooting training, the experiment presents research on four catching positions as shown in the Fig. (6).

It is observed from Fig. (6) that the minimum pitching velocity in every catching position is marked with ' $*$ ' and the minimum initial velocity vmin and the value of horizontal included angle $\theta$ to satisfy the requirement of catching are indicated on the right side of every curve. 


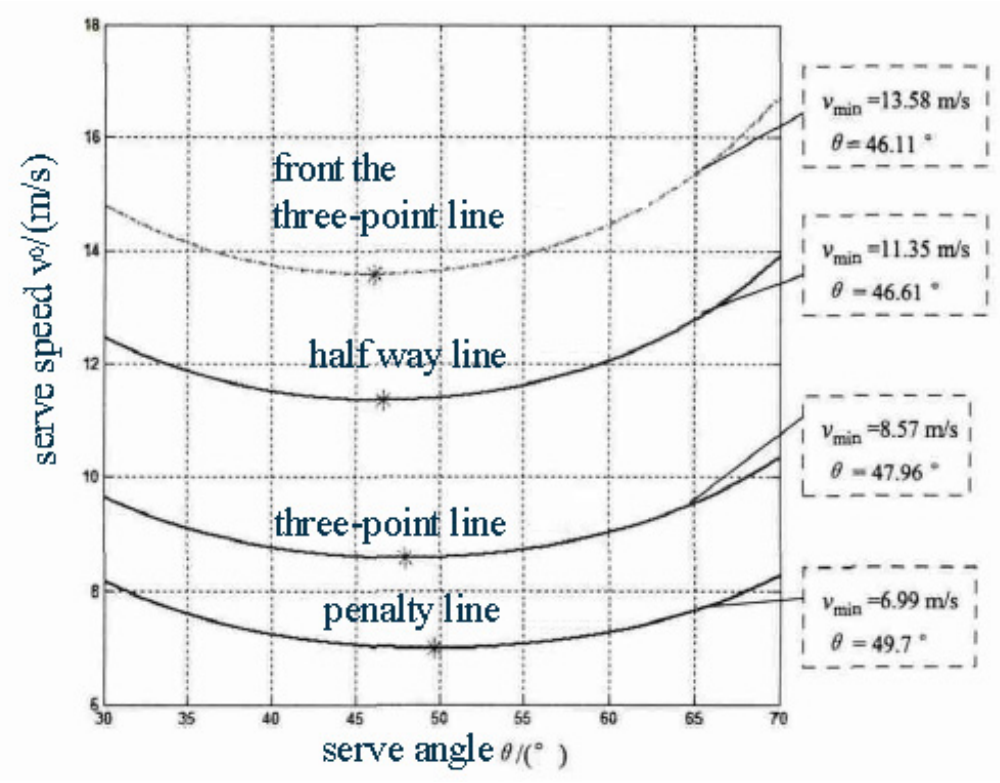

Fig. (6). Relation curve between shooting angle and velocity in different catching positions.

It is observed from further analysis on experimental result that when the catching position is fixed, the relation between initial velocity and horizontal included angle can be described by quadratic curve, and there is minimum value for initial velocity and the angular velocity and rotating velocity of friction wheels and motor in pitching machine are determined according to minimum value $\mathrm{v}_{\min }$. In addition, it is also observed from the result that the farther catching position shall need faster initial velocity for normal catching and smaller horizontal included angle.

Improvement in technical level for basketball requires the hard training in normal times, together with auxiliary apparatus of basketball for intensive training. Pitching machine for basketball plays a key role in improvement of technical level and has significant influence on basketball players.

Chest passing and catching with both hands is characterized by fast velocity and powerful strength in basketball skill, in order to better grasp the skill, the motion effect of pitching machine for basketball shall be brought into full play so as to combine chest passing and catching with both hands with other basketball skills, thus improve players' professional skills.

Chest passing and catching with both hands is the basis of passing skill in basketball. It is necessary and proper to practice chest passing and catching with both hands to improve passing skill.

During chest passing and catching with both hands, the player should hold the ball between chest and belly with both hands, namely the flared position in costal bone, position of "eight" shape. When player holds the ball, his or her elbows should bend naturally, with eyes looking at the front horizontally, when the player is to pass the ball, he or she shall exert force by stepping on the ground with rear foot to shift self physical gravity and stretch out arms, with wrists turning internally and thumbs pushing downward the basketball to make his or her first fingers and middle fingers to pass the ball with upward force.
After the basketball is off hands, both hands shall turn outwardly to a certain extent.

For chest passing and catching with both hands, it is necessary to keep standard holding posture and standing posture. In addition, it is necessary to ensure coordination and coherence in finger rolling and passing. On the premise of proper control of self gravity, the player's arms shall be free of additional action.

In practicing chest passing and catching with both hands, the player can ask help from partner for face to face practice. One player also can practice the skill with the help of wall elastic force. When you make a dent in it, you may proceed to practice in motion. The motion analysis of pitching machine for basketball based on MATLAB plays an important role in improvement of basketball skill.

\section{CONCLUSION}

The paper presents detailed analysis on the basic principle of chest passing and simplification of the process to obtain a dual wheel type pitching machine, based on which tobuild a mathematical model for movement of flying basketball, then shows the analysis of four catching positions based on MATLAB simulation technique to obtain the value range for the parameters of these positions and calculate minimum initial velocity and horizontal included angle needed for effective passing, thus provide the theoretical basis for development and utilization of pitching machine for basketball.

\section{CONFLICT OF INTEREST}

The authors confirm that this article content has no conflict of interest.

\section{ACKNOWLEDGEMENTS}

Declared none. 


\section{REFERENCES}

[1] J. Ma, and Y. Shi, "Comparison of Analysis on Passing Skill Given in Basketball Works in China and US," Journal of Capital Institute of Physical Education, no.1, pp. 52-57, 2014. http://caod.oriprobe. com/articles/41340149/Comparison_of_the_Analysis_of_Pass_rece iving Techniques in Basketball .htm

[2] B. Wang, "Foundation of Aerodynamics" Beijing: National Defence Industry Press, no.05, pp. 33-36, 2012.
[3] Y. Fan, and R. Cen, "Motion Technical Analysis based on Oblique Projectile Kinematical Equation" Biomedical Engineering Research, no.2, pp. 22-23, 2012.

[4] W. Liu, "MATLAB Program Design and Application (Edition II)," Beijing: Higher Education Press, no.10, pp. 33-34, 2012.

[5] W. Xue, "A Hollow Pitching Machine for Basketball Applicable to Basketball Teaching and Training", China, CN 201220428257, 2012.

[6] Y. He, and J. Xiang, "Basketball Training Machine," China, $201020032059,2010$.

[7] G. Wen, and L. Chen, "Automatic Pitching Machine for Basketball Training”, China, CN 201320023595, 2013.

Received: June 10, 2015

Revised: July 29, 2015

Accepted: August 15, 2015

(C) Yang Wen-Xian; Licensee Bentham Open.

This is an open access article licensed under the terms of the (https://creativecommons.org/licenses/by/4.0/legalcode), which permits unrestricted, noncommercial use, distribution and reproduction in any medium, provided the work is properly cited. 